\title{
Interprofessional education and high-fidelity simulation teaching in medical and nursing students in Peking Union Medical College
}

\author{
Huan Cheng^, Liping $W u^{\wedge}$ \\ Shool of Nursing, Peking Union Medical College, Beijing, China \\ Correspondence to: Liping Wu, PhD. Shijingshan District, Beijing 100144, China. Email: wuliping2014@163.com.
}

Received: 19 May 2021; Accepted: 30 August 2021; Published: 25 March 2022.

doi: 10.21037/jhmhp-21-39

View this article at: https://dx.doi.org/10.21037/jhmhp-21-39

\section{Introduction of Peking Union Medical College (PUMC)}

PUMC, founded in 1917, is the first key medical school to offer eight-year curriculum on clinical medicine and undergraduate courses on nursing in China.

The School of Clinical Medicine of PUMC, which is also known as Peking Union Medical College Hospital (PUMCH), takes seriously the idea of being "small but excellent". It has remained committed to keeping enrollment small, maintaining strict teaching standards, and producing quality graduates. Presently, there are more than 600 postgraduate students in the school, and more than 2,000 have graduated since its founding.

In 1920, PUMC became the first institution to offer higher nursing education in China. In 1996, the School of Nursing began offering a Master's degree in nursing, and launching a doctoral program in 2005. The school of Nursing has a national teaching team and an excellent teaching environment.

\section{Background and goals of the Interprofessional Education (IPE) research}

IPE refers to the integration of the cooperative principle in social psychology into teaching practice based on cooperative learning strategies. At least two from different majors learn from each other and understand each other in order to strengthen cooperation and improve the quality of care (1). In 2010, the International Committee of Experts on Medical Education published a report in The Lancet, which clearly pointed out that IPE should be strengthened in the 21 st century (2). Physician-nurse cooperation learning is a form of IPE. Students majoring in nursing (referred to nursing students) and students majoring in medicine (referred to medical students) cooperate to learn, with the purpose of enabling students majoring in medical care to learn from each other and effectively cooperate, and ultimately improve patients' health (3). Study of the Institute of Medicine (IOM) shown that patients are more likely to get safe and high-quality services when medical professionals understand each other's roles and can effectively communicate and cooperate (3). The American Association of College of Nursing (AACN) proposed in 2008 that improving health outcomes of patients through IPE is one of the nine basic goals of undergraduate nursing education (4). Domestic research on IPE in medical and nursing students started relatively late, and relevant reports only appeared in clinical practice in the early 21 st century (5). At present, the model of physician-nurse cooperation learning is getting more and more attention from Chinese medical educators and managers.

High-fidelity simulation based on the physical drive technology, which simulates the clinical actual situation as the prerequisite, with practice teaching, situational teaching and individualized teaching as the characteristics. It has the outstanding advantage of a medical risk-free environment. Studies $(6,7)$ have shown that the effect of high simulation teaching is remarkable, which is embodied in the following two aspects: firstly, it helps to set up a scientific concept of nursing. Secondly, it is helpful to cultivate the competency of nurses. However, traditionally, medical students and nursing students are trained separately and only focus on

^ ORCID: Huan Cheng, 0000-0001-8454-2584; Liping Wu, 0000-0003-2660-3486. 
their own fields and deal with problems according to their inherent thinking, ignoring the cultivation of teamwork consciousness and medical communication ability $(8,9)$.

At present, most Master of Nursing Specialist (MNS) students in China are fresh graduates $(10,11)$ and enter the postgraduate stage through the recommended examfree or national postgraduate entrance examination. Most of the students lack of work experience, while the clinical teachers who can guide professional degree graduates in the clinical stage are insufficient, and the level of academic qualifications of tutors with clinical experience in hospitals is limited. Since 2011, the School of Nursing, PUMC has offered a clinical thinking training course for MNS postgraduates. Various teaching methods, such as case discussion, analysis and situational simulation teaching, have been adopted to improve the ability of MNS postgraduates to collect clinical data, analyze problems, and deal with problems. In addition, in clinical thinking training courses for MNS graduate students in 2015 and 2016, we tried to carry out multidisciplinary cooperative situational simulation teaching and achieved good teaching effect (12). However, the role of doctors involved in the scene is mainly played by the nursing teacher. As the designer of the case, the teacher anticipated the progress of the disease in the case in advance, and had a strong situational control over the case, so the scene was not real enough. The latest advancement of medicine in the cases were not fully discussed and it was difficult to train medical students and nursing students to communicate and cooperate.

Medical students and nursing students cooperate to conduct interdisciplinary and cross-course simulation teaching, which integrates IPE and simulation teaching to make up for the shortcomings of traditional separation simulation. It can realize the complementary advantages of medical students and nursing students. It is helpful to cultivate and train students' awareness and attitude of medical cooperation, enhance the cultivation of medical communication and cooperation ability, thus to establish clinical thinking and solve practical problems. Therefore, this study hopes to explore a high simulation teaching mode suitable for medical cooperation.

\section{The process of the IPE research}

\section{Expert seminar}

At the beginning of the establishment of the project, an expert seminar was held, including five teachers with the title of associate professor or above from the School of Nursing, and clinicians, head nurses and nursing teachers from PUMCH, and an associate professor from the school of humanities PUMC. Moreover, the director of Gunma University Centre for Research and Training on IPE attended this seminar. After this expert seminar, the following issues were identified. First of all, the time and place of training were taken into consideration, in this regard, the time for medical students and MNS students to enter clinical rotation was considered. Experts agreed that students need to have relevant theoretical knowledge, clinical experience and certain skill reserve before they can participate in the medical cooperation scenario simulation training. The second was about the grouping of students. Referring to the situation simulation of medical students in the past, each group should not have too many students, and 3-5 students should be appropriate. In addition, case preparation is an important part. To select real clinical cases, the team set different teaching objectives in different cases, from easy to difficult, and gradually cultivate were accepted by experts. In this seminar, the experts formed different groups according to their respective work directions, responsible for case preparation and control of simulation training.

\section{Case collection and compilation}

The case collection should follow the principles of authenticity, clinical commonness and strong operability. According to the theory of situational cognition, students can better learn what to do and how to do in a real clinical environment. In order to reflect this sense of reality in the cases, we chose real clinical cases as the basis of compilation. We not only collected objective clinical data, but also collected the emotional changes of patients during the treatment process, so that the cases could get closer to the clinic. We paid attention to retaining the main content of the original cases, objectively and truly described the scenes and plots of the cases, and did not include the editor's own views. In the process of case compilation, it is necessary to draw a flow chart according to the teaching objectives.

\section{Form case scripts}

The case scripts were divided into 4 versions, including teacher version, student version, laboratory version, and standardized patient version. The teacher version is the most detailed, and it was divided into two parts. The first 
part described the patient's original case, the occurrence, development, treatment and care of the disease. The second part included the artificial scenarios and the teaching objectives and tasks of each scenario. However, teaching objectives and tasks are different for different majors. The student version includes the basic information of the patient, such as age, complaint, symptoms, etc. and the introduction of each artificial scenario. Students will complete the content of each scenario based on the information provided. In addition, it also included the knowledge and skills needed to prepare for class, so that students could make preparations in advance. The lab version introduces the various experimental tools used in the simulation training process, especially the preparation of the environment, we need to make the scene as realistic as possible, the standardized patient version included the patient's basic information, such as age, native place, education and so on, as well as physical signs and emotional changes in each artificial scenario. The four versions complement each other to ensure the smooth implementation of IPE simulation training.

\section{First run of IPE simulation training}

An obstetrical case was selected for the first run of the IPE simulation training, and the participants included the research leader, a professor of obstetrics and gynecology at the School of Nursing, two nursing teachers from the hospital, a clinician, and five students (a sixth-year medical student, two second-year MNS students, and two firstyear MNS students). The role of the medical student is doctor. Two senior MNS students act as a senior nurse A and a junior nurse B respectively. The patient is played by a first-year MNS student, and the other student is responsible for the whole process of video recording. One week before the start of the simulation, students and teachers received information about the case. There are three scenarios in this simulation, namely, patient admission assessment, condition decision and postoperative handover. It took about one hour. In the first scenario, the students completed an admission evaluation of the patient based on the information given to them. The patient, the doctor, and the nurses discussed the condition together. The first scene took about 25 minutes to complete. In the second scenario, the patient's condition changed badly and the pregnancy needed to be terminated in advance. The doctor explained the condition and discussed with the patient about the decision. The nurses found and comforted the patient in time when the patient's mood changed, then the nurses made preoperative preparations for the patient. There are a lot of communication skills involved in this process. It took about 15 minutes. The third scene was the handover between doctor and nurses after surgery. This scene was relatively short and took about 6 minutes to complete. In this scenario simulation, all the students excellently completed their roles and tasks, enhanced their awareness of medical communication and understood the importance of medical cooperation.

\section{Discussion}

IPE and high-fidelity simulation teaching in medical and nursing students is a new attempt. It's a little bit different from previous scenarios. In the previous simulation, the role of doctor is often played by teachers or nursing students. Teachers, as the designers of cases, tend to predict the progress of cases in advance, while nursing students who acted as doctors tend to be nervous in simulation due to lack of knowledge, which will affect the simulation experience (13). Students from different majors work together to enhance their understanding of different majors. It promotes more effective communication between doctors and nurses.

Nowadays, various medical colleges actively carry out simulation training, but there are few simulation trainings of IPE. More and more educators are paying attention to the importance of IPE. It was the first time that PUMC tried IPE and high-fidelity simulation teaching in medical and nursing students. At present, this program was just getting started, and it wasn't thorough, especially assessment tools. And we are also communicating with other institutions to learn from their experience. In the process of the first run, due to the lack of appropriate assessment tools, we only talked to the participating students after the end. However, through students' descriptions, we could understand students' experience in IPE and possible problems in the program. At present, the evaluation methods, contents and tools of IPE and high-fidelity simulation teaching in medical and nursing students in China are still not perfect at present, which is also an important part of our next work.

\section{Acknowledgments}

The authors are grateful to Professor Hong Zhao and Professor Yang Li from School of Nursing, PUMC, and Dr. Min Luo, Mrs. Changjie Yang, and Mrs. Dongmei Lian 
from Peking Union Medical College Hospital for their kind support of this study.

Funding: This work was supported by Project of Peking Union Medical College (10023201802501).

\section{Footnote}

Provenance and Peer Review: This article was commissioned by the Guest Editor (Takatoshi Makino) for the series "Interprofessional Education in Asia" published in fournal of Hospital Management and Health Policy. The article has undergone external peer review.

Conflicts of Interest: Both authors have completed the ICMJE uniform disclosure form (available at https://jhmhp. amegroups.com/article/view/10.21037/jhmhp-21-39/ coif). The series "Interprofessional Education in Asia" was commissioned by the editorial office without any sponsorship or funding. The authors have no other conflicts of interest to declare.

Ethical Statement: The authors are accountable for all aspects of the work in ensuring that questions related to the accuracy or integrity of any part of the work are appropriately investigated and resolved.

Open Access Statement: This is an Open Access article distributed in accordance with the Creative Commons Attribution-NonCommercial-NoDerivs 4.0 International License (CC BY-NC-ND 4.0), which permits the noncommercial replication and distribution of the article with the strict proviso that no changes or edits are made and the original work is properly cited (including links to both the formal publication through the relevant DOI and the license). See: https://creativecommons.org/licenses/by-nc-nd/4.0/.

\section{References}

1. Gilbert JH, Yan J, Hoffman SJ. A WHO report: framework for action on interprofessional education and collaborative practice. J Allied Health 2010;39 Suppl 1:196-7.

2. Frenk J, Chen L, Bhutta ZA, et al. Health professionals for a new century: transforming education to strengthen health systems in an interdependent world. Lancet 2010;376:1923-58.

3. Feather RA, Carr DE, Garletts DM, et al. Nursing and medical students teaming up: Results of an interprofessional project. J Interprof Care 2017;31:661-3.

4. Defenbaugh N, Chikotas NE. The outcome of interprofessional education: Integrating communication studies into a standardized patient experience for advanced practice nursing students. Nurse Educ Pract 2016;16:176-81.

5. Zhou MZ, Zhang YJ. Strengthen medical cooperation to improve the overall quality of care. Hospital Administration Journal of Chinese People's Liberation Army 2000;7:208.

6. Zhao LY, Tu LX, Su CJ, et al. Application of Core Competence of Higher Vocational Nursing Students Based on Simman Comprehensive Simulated Human Training. Nursing Practice and Research 2012;9:97-9.

7. Bai BX, Ke YY, Li M. Application progress on high simulation teaching in nursing science. Chinese Nursing Research 2015;29:1416-9.

8. Yang Y, Liu HP. Systematic evaluation influence of high fidelity simulation teaching on clinical competence of nursing students. Chinese Nursing Research 2016;30:809-14.

9. Gu YH. Application and Effect of High-fidelity Simulation in Nursing Undergraduate Education. Nursing Journal of Chinese People's Liberation Army 2016;33:53-6.

10. Zhao QH, Xiong Q, Xie LL. et al. Practice of tutor group model for postgraduate nursing education. Chinese Nursing Management 2015;15:190-2.

11. Li JP, Zhang YF, Li L. The training of clinical practice capability of students in master of nursing specialist programs. Chinese Journal of Nursing Education 2015;12:730-4.

12. Wu LP, Guo AM, Yang H, et al. Application of simulation teaching based on multi-disciplinary cooperation in clinical thinking training course for master of nursing specialist. Chinese Nursing Management 2018;18:927-30.

13. Zhu FF, Wu LR. The evaluation of the teaching effects of nursing students based on different roles in high-fidelity simulation teaching. Chinese Nursing Management 2016;16:76-9.

doi: $10.21037 / \mathrm{jhmhp}-21-39$

Cite this article as: Cheng $\mathrm{H}, \mathrm{Wu} \mathrm{L}$. Interprofessional education and high-fidelity simulation teaching in medical and nursing students in Peking Union Medical College. J Hosp Manag Health Policy 2022;6:10. 